\title{
The Reform Practice of Bridge Structure Analysis Software Course Under the Background of Engineering Talents Training
}

\author{
Jing-xian $\mathrm{SHI}^{1 *}$ \\ ${ }^{1}$ Oxbridge College, Kunming University of Science and Technology, Kunming, Yunnan 650102, China \\ *Corresponding author. Email: sara_shivip@163.com
}

\begin{abstract}
This paper expounds the position and nature of the software course of bridge structure analysis. According to the employment situation of students in the direction of civil engineering road and bridge, also the demand for the application of engineering structure analysis software, the paper establishes the main idea of "case driven, knowledge point combined with software module" as the curriculum construction. Under the guidance of this idea, we have developed appropriate teaching materials, combined with cases, micro courses and other means, and made a useful research in the construction of curriculum system.
\end{abstract}

Keywords: teaching, bridges, structural analysis software, curriculum construction

\section{THE SIGNIFICANCE OF CURRICULUM REFORM}

\subsection{The Demand of Training Industrial Talents}

Under the situation of the national teaching comprehensive reform in full swing, the "application-oriented" transformation of many private colleges and universities has opened the curtain of the teaching reform. The application-oriented undergraduate education belongs to the higher level of technical education, which trains the higher technical application talents to meet the needs of production, construction, management and service.

Our university is a provincial "application-oriented talent training demonstration college", which has some reform research achievements in high-level discipline construction research, application-oriented talent training mode innovation, new engineering construction and so on. The training mode of our university is to build the curriculum and teaching content system with "application" as the theme and characteristics, and pay special attention to the training of students' ability of technical application. The engineering specialty aims to cultivate "Engineering" talents.

\subsection{The importance of the course}

<The application of bridge structure analysis software> is a technology application course. Midas civil--the software used in the course, is also frequently used in design institutes and construction units. It is widely used in design, construction analysis, load test and other fields; the main employment direction of civil engineering students is design Institute, construction unit and testing unit. These units have certain requirements for the application ability of software, so the practical courses such as structural analysis software are particularly important.

In the last semester of the senior year, our students will have nearly one semester of production practice. The purpose is to integrate theory with practice, learn knowledge of construction and management, and cultivate the ability to analyze problems and solve practical production problems independently. Many units have certain requirements for the application ability of bridge structure analysis software, so learning this series of software before production practice is very helpful for practice and even later work.

\section{TEACHING SITUATION}

\subsection{Improper teaching arrangement}

At present, <the application of bridge structure analysis software > set up by our school is to study Midas civil. The number of students to select for this course is about 150 each year, which is arranged in the final practice and carried out in a decentralized way. The course will last 2 weeks, and it is difficult for students to complete a simple beam structure design by self-study and independent operation due to no theoretical study in the final practice. This practical course emphasizes on teaching with students, and urges students to explore and think independently in teaching activities. However, the overall autonomous learning ability of students is weak, especially in the comprehensive courses. Students are more dependent on Teachers and leads to insufficient use of the originally 
tense class hours. Therefore, the credit of this course should be adjusted.

At present, the software teaching class focuses on the operation of design. However, the direction of most graduates majoring in civil engineering in our university is construction unit, testing unit, and so on. These units use Midas civil bridge structure analysis software frequently. Therefore, students should be taken into account in the course of bridge structure analysis software.

\subsection{Lack of proper teaching materials}

At present, there is no special textbook for <the application of bridge structure analysis software $>$, but only a few related monographs. There are several problems in these monographs:

(1) Most of the software versions published before 2016 are relatively out of date and should be replaced by new versions;

(2) many old versions of the calculation results are inconsistent with the current specifications after the implementation of the new concrete specification 2018;

(3) The recent books are very in-depth, but the content is single and the knowledge is specific to a certain field, so they are not suitable for teaching materials.

\section{TEACHING REFORM MEASURES}

The curriculum reform of <the application of bridge structure analysis software $>$ will be based on the background of civil engineering innovation and application-oriented personnel training, and according to the teaching objectives of the course, select the teaching content, enrich the teaching means, and improve the comprehensive quality of students.

\subsection{The construction of teaching system}

The construction of curriculum system is not simply based on calculation, but on the whole modern education theory. We will build a system with capacity-building as the teaching content. In the teaching process, we should fully investigate the needs of enterprises, optimize and integrate the curriculum system, and combine the software module with the course content to realize the optimized knowledge point system of case driven teaching.

Therefore, we change this course to compulsory course, which is put in the practice teaching, with 3 credits and 48 class hours in total. This course is suitable for junior students majoring in Civil Engineering (road and Bridge Engineering), and the first courses are bridge engineering and $\mathrm{CAD}$, and the subsequent courses are graduation design.

\subsection{Compile appropriate teaching materials}

In view of the curriculum objectives of <the application of bridge structure analysis software> and the actual situation of the current students in the school, the textbook is divided into three core contents: using software to solve mechanics knowledge, bridge structure design and construction auxiliary design analysis. The core contents of the new textbook are as follows:

(1) Software introduction and menu modeling function introduction.

(2) Learn structural mechanics with midas Civil:

1) Calculation of simply supported beam: The modeling analysis of $10 \mathrm{~m}$ rectangular section bridge;

2) Continuous beam calculation: Expound the internal force and deformation of continuous beams with different sections;

3) Arch structure calculation: The arch structure analysis of different span is expounded.

(3) Using software to design bridge structure: Taking the prestressed concrete simple supported beam bridge designed in the course of bridge engineering as an example, explain the application of PSC design function of software in bridge design.

(4) Using software to solve the analysis of temporary construction structure: Taking the most commonly used universal member tower in bridge construction as an example, the application of software stability analysis in bridge construction is explained.

(5) Use software to solve the cantilever construction problem: Taking the cantilever construction of continuous rigid frame bridge as an example, explain the application of modeling assistant in construction stage analysis.

(6) Comprehensive ability training: Taking the continuous rigid frame bridge constructed by cantilever as an example, explain the PSC design method.

\subsection{Teaching method}

(1) Case teaching method: According to the system of knowledge point learning, application cases are given for each knowledge point, through the application of case penetration method. Students are encouraged to learn from the perspective of practicality and apply the knowledge modules learned in class to project practice.

(2) Combination of teaching resource base. In order to cooperate with the theory teaching and achieve good teaching effect, building teaching resource base with Midas Company. It can be used by students and teachers by means of network teaching resources, electronic teaching materials and case demonstration, so that teaching methods can be truly applied in the actual teaching process.

(3) Key knowledge and difficult of micro course teaching: Set up modern teaching methods by using mobile phone. In view of some difficulties, such as, input and adjustment of prestressed steel tendon, division of construction stages. 
Micro lessons are recorded and transferred to the mobile classroom, so that students can learn at any time after class. (4) Structure design competition driven Teaching: There is a calculation part in these structural competitions, such as Structural design competition for College Students, National University Student Bridge modeling competition, etc. This part requires students to carry out mechanical analysis on the structure by using Structural analysis software. The combination of curriculum and structure competition can greatly promote students' interest in learning, and it is a very effective way to urge students to study independently.

\subsection{Making digital teaching knowledge points}

The deep integration of information technology and education and teaching has become an inevitable trend in "Internet +" era. In the course of teaching for several years, we found several knowledge points and operations that are difficult for students to understand, in view of the following points, and the micro class is made.

(1) Variable section and variable section group: Variable cross-section refers to the cross-section form of a unit; for a group of continuous units, when the cross-section type is the same and the change form is the same, the function of variable cross-section group can be used.

Through the definition of a group of beam element sections, this paper demonstrates how to define the variable section and the variable section group, and their respective application scope.According to this part of knowledge, the duration of the online micro-lesson is about 6 minutes.

(2) Definition of prestressing load: The pre-stressed load of steel tendons is to simulate the function of the prestressed steel tendons in the pre-stressed concrete structure.

In the program, there are three steps: defining the properties of prestressed tendons, defining the layout shape of prestressed reinforcement, and inputting the tension control stress. According to the knowledge in this part, the duration of the online micro-lesson is about 10 minutes.

(3) Time dependent materials: The shrinkage and creep characteristics of concrete and the time-dependent properties of concrete strength collectively referred to time-dependent material properties in the program.

There are three steps to define the time dependent material properties of concrete: Define time-dependent property function (including shrinkage creep function and strength development function) - connect the defined timedependent property function with the corresponding material - modify the time-dependent material property value. Aiming at this knowledge point, the duration of the online micro-lesson is about 8 minutes.

(4) Construction stage: Firstly, explain the theoretical significance of construction stage in model analysis and design. Learn to define groups, and then explain the activation and passivation methods of boundary conditions, units, etc. in each construction stage.
This knowledge point is very difficult. The online microlecture for it lasts about 12 minutes and arranges a lot of exercises.

\section{CONCLUSION}

The curriculum reform of $<$ Application of bridge structure analysis software>is guided by the concept of applied talents training, and it has established the construction idea of application-oriented personnel training suitable for the characteristics of our university. Through several years of teaching exploration and practice, the teaching system of "case driven knowledge points combined with software modules" has been established. Under the guidance of this kind of thinking, the textbook suitable for the basic situation of the school should be compiled.

This paper gives the knowledge point system of teaching materials, and takes case teaching method as the main means, using case teaching, micro class and other teaching methods, and it will be applied to 2019-2020 academic year teaching practice, hoping to achieve better teaching results. In the next step, we will strive to build <Application of bridge structure analysis software> as a high-quality demonstration course to promote professional construction.

It is a long-term topic to cultivate engineering talents that meet the needs of the society through good course construction and teaching quality. It is not only the important responsibility of our teachers, but also the important goal of our course construction.

\section{ACKNOWLEDGMENT}

This work was supported by Kunming University of Science and Technology Education Reform Project:Reform and Practice of the Teaching System of the Course "Application of Engineering Structure Analysis Software" Based on the Training of Applied Talents.

\section{REFERENCES}

[1] ZHOU Shui-xing, Calculation of Bridge StructuresFinite Element Analysis and Its Application in MIDAS / Civil. in: China Communications Press.

[2]CHEN Ji-hao,QIAN Xiao-jun,Teaching Status and Reform of Engineering Structure Computing Software Course,China Electric Power Education,2014,pp.104107.

[3]LI Cheng-tao, HAN Jia-hui,WANG Jiahong,WANG Sen.The Reform and Practice of the Training Mode of Environmental Professionals Oriented by the Training of Engineering Practice Ability,in EDUCATION TEACHING FORUM.2020,pp.134-135. 
vocational education system [J]. Higher Education Academic Journal, 2019,12, pp. 153-158.

[6] CHEN Ji-hao. Teaching Status and Reform of "Engineering Structure Computing Software" Course [J] . In China Electric Power Education, 2014 (12), pp.104-105.
04, pp. $452-458$

[5] GONG Dan. On the training mode of applied undergraduate talents from the perspective of modern 